\title{
Erratum to: Multi-Atlas Library for Eliminating Normalization Failures in Non-Human Primates
}

\author{
Joseph A. Maldjian ${ }^{1,2,3} \cdot$ Carol A. Shively ${ }^{4}$ Michael A. Nader ${ }^{5}$ • David P. Friedman ${ }^{5}$. \\ Christopher T. Whitlow ${ }^{1,2}$
}

Published online: 1 September 2016

(C) Springer Science+Business Media New York 2016

Erratum to: Neuroinform (2016) 14:183-190

DOI 10.1007/s12021-015-9291-4

In the Acknowledgments section of the original version of the article, the following information is missing:

This study was also supported in part by the National Institute on Alcohol Abuse and Alcoholism: AA019431, AA017710 and AA016748 (James B. Daunais).

The online version of the original article can be found at http://dx.doi. org/10.1007/s12021-015-9291-4

Joseph A. Maldjian

joseph.maldjian@utsouthwestern.edu

1 Advanced Neuroscience Imaging Research (ANSIR) Laboratory, Wake Forest School of Medicine, Winston-Salem, NC 27157-1088, USA

2 Department of Radiology, Wake Forest School of Medicine, Winston-Salem, NC 27157-1088, USA

3 Department of Radiology, University of Texas Southwestern Medical, Center, 5323 Harry Hines Blvd, Dallas, TX 75390-8896, USA

4 Department of Pathology, Wake Forest School of Medicine, Winston-Salem, NC 27157-1088, USA

5 Department of Physiology and Pharmacology, Wake Forest School of Medicine, Winston-Salem, NC 27157-1088, USA 